\title{
Sweet Corn Yield Simulation Using Normalized Difference Vegetation Index and Leaf Area Index
}

\author{
Pavlo Lykhovyd ${ }^{1}$ \\ 1 Department of Scientific and Innovative Activity, Transfer of Technologies and Intellectual Property, Institute \\ of Irrigated Agriculture of NAAS, Naddniprianske, 73483, Kherson, Ukraine \\ e-mail: pavel.likhovid@gmail.com
}

\begin{abstract}
The authors determined the accuracy and reliability of yielding models by using the values of two differently obtained indices - the leaf area index (LAI) obtained through direct surface measurements, and the normalized difference vegetation index (NDVI) obtained through spatial remote sensing of crops. The study based on the drip-irrigated sweet corn yielded the data obtained in the field experiment held in the semi-arid climate on darkchestnut soil in the South of Ukraine. The suitability of the LAI and NDVI for the simulation of sweet corn yields was estimated by the regression analysis of the yielding data by correlation $(\mathrm{R})$ and determination $\left(\mathrm{R}^{2}\right)$ coefficients. Additionally, mathematical models for the crop yields estimation based on the regression analysis were developed. It was determined that LAI is a more suitable index for the crop yield prediction: the $\mathrm{R}^{2}$ value was 0.92 and 0.94 against 0.85 for the NDVI-based models.I It was determined that it is better to use the LAI values obtained at the stage of flowering, when $\mathrm{R}^{2}$ averaged to 0.94 , and the NDVI-based models does not depend on the crop stage (the $\mathrm{R}^{2}$ was 0.85 both for the flowering and ripening stages of the plant development). The combined NDVI-LAI model showed that there is no necessity in the complication of the LAI-based model through introduction of the remotely sensed index because of insignificant improvement in the performance $\left(\mathrm{R}^{2}\right.$ was 0.94 and 0.92$)$.
\end{abstract}

Keywords: direct measurements, mathematical model, regression analysis, remote sensing, sweet corn, yield prediction.

\section{INTRODUCTION}

Modern agriculture is inseparably linked with information technologies, especially mathematical and statistical modeling, geo-informational technologies (GIS), remote sensing technologies for environmental monitoring, etc. It is necessary to develop and apply in production new approaches for the prediction of crop yields through the mathematical estimation of the productivity related indices, especially, an important modern index obtained by the remote sensing - the normalized difference vegetation index (NDVI). The use of remotely sensed index provides the possibility of making on time predictions of the crops productivity and does not require complicated and prolonged in-field measurements to obtain the input data for the forecasting (Kouadio et al., 2014). Moreover, the NDVI screens are mostly provided in a timely manner and often are free of charge that makes the use of the index more attractive even for the little-scale farmers and scientific institutions with a limited budget (Maas, 1988; Atzberger, 2013). NDVI is obtained through the space sensing and calculated by the Eq (1):

$$
N D V I=\frac{\left(a_{\text {nir }}-a_{v i s}\right)}{\left(a_{\text {nir }}+a_{v i s}\right)}
$$

where: $a_{n i r}$ is the reflective infrared range of the spectrum, $a_{v i s}$ is the visible red range of the spectrum (Carlson and Ripley, 1997).

It is considered that the NDVI values are strongly dependent on the indices of the crops, namely: leaf area index (LAI), herbage development, general development of the vegetative cover, etc. (Gamon et al., 1995; Carlson and Ripley, 1997). For example, Gamon et al. (1995) determined that the NDVI and LAI provided the 
strong correlation with the coefficients of 0.912 (for total LAI) and 0.949 (for green LAI). Thus, the NDVI could be possibly used as an alternative for the LAI, which is calculated as the ratio of the leaf surface area of plants to the total area of the covered land (Bréda, 2003), to provide a comprehensive and reliable assessment of the crop conditions and projective productivity.The NDVI is believed to be an indicator of the potential photosynthetic activity of plants, and, as a result, the index of the phytocenosis productivity (Sellers, 1985; Myneni et al., 1995).

Therefore, the main goal of our study was to determine whether it is possible to completely replace the conventional crop productivity indices (for example, the directly measured LAI) in the crops productivity models with the spatial NDVI. Therefore, the authors decided to perform yield prediction modeling based on the LAI and NDVI values on the example of a sample crop (sweet corn) and compare the accuracy and reliability of each forecasting method. It is necessary because if the NDVI-based crop prediction models are to be used, it is necessary to know all the weak and strong points of this kind of models.It is known that the spatial NDVI data are often not a reliable source of the information on the crop condition due to the dependence of the NDVI values on a number of parameters, namely: the quality of the NDVI screening equipment; the conditions of weather, especially cloudiness that can deteriorate the quality of the screening; the soil reflective ability that often leads to the disturbances in the screening of the real NDVI values; violation of a direct correlation between the NDVI and other vegetation-related indices (such as LAI) with the increased vegetation mass development (Liu and Huete, 1995). Moreover, the authors performed a combined yield modeling by parallel implementation of both LAI and NDVI as the inputs for the crop model to find out whether a combined use of these crop indices improves or, conversely, deteriorates the accuracy and reliability of the yielding model.

\section{MATERIALS AND METHODS}

The authors chose sweet corn (Zea mays L. ssp. saccharata Sturt.) cultivated in the field experiment on the cultivation technology elements (plowing depth, fertilization and plants density) estimation at drip irrigation in the semi-arid climate zone of the South of Ukraine as a sample crop for the conduction of the prediction model's assessment. The geographical coordinates of the experimental field are: $46^{\circ} 68^{\prime} \mathrm{N}, 32^{\circ} 26^{\prime} \mathrm{E}$, the altitude of $42 \mathrm{~m}$. The scheme of the experiment, which was conducted in 2016, is as follows:

- Factor A - plowing depth: 20-22 and 28-30 $\mathrm{cm}$;

- Factor B - mineral fertilizers applied: No fertilizers, $\mathrm{N}_{60} \mathrm{P}_{60}, \mathrm{~N}_{120} \mathrm{P}_{120}$;

- Factor $\mathrm{C}$ - plants density (this parameter was finally formed manually at the stage of 3-5 leaves of the crop): $35,50,65,80$ thousand plants per ha.

In order to evaluate the accuracy of the yield predictions by the different modeling approaches, the yield of the crop in the ears without husks was assessed at the stage of the technical ripeness through the picking and weighing of the ears from the entire area of every experimental plot (in 4 replications). Picking and weighing were performed in accordance to methodology of the experimental work in irrigated agriculture which is generally accepted in the South of Ukraine (Ushkarenko et al., 2014). Only marketable ears were used in the assessment.

The NDVI values were obtained by using the system of precise agriculture OneSoil ${ }^{\circledR}$ (onesoil. ai/en), which provides the screens of fields from satellites Sentinel-1 and Sentinel-2. The system provides the accuracy of recognition $F_{1}$ of 0.9 , the speed of the artifacts processing of $30 \mathrm{~ms}$, the accuracy of the automatic field borders recognition IoU of 0.85 . The NDVI values were taken by all the replications of the study using the scaled screens obtained at the certain periods of the crop development (flowering and ripening stages) on July, $14^{\text {th }}$ and July, $26^{\text {th }}$, 2016. LAI was calculated by the results of the direct field measurements of the leaf area of the plants per the unit of area considering the density of the crops (Ushkarenko et al., 2014). The leaf area measurements were performed using a common ruler. The withered leaves were not taken into consideration, so only pure green LAI were obtained and estimated in the study. LAI was calculated by using Eq. (2):

$$
L A I=\frac{L A \times P D}{10000}
$$

where: $L A$ is the leaf area per plant $\left(\mathrm{m}^{2}\right), P D$ is the plants density on the experimental plot. 
All the data obtained and used in the work were processed by using the multiplicative ANOVA and linear regression analysis at the probability level of $95 \%$ with further building up the model for the yield prediction based on the calculated regression coefficients. Standard calculation procedures were used and performed in the Microsoft Excel software (Triola, 2013). The significance of the differences between the studied experimental variants was assessed using the least significant difference $\left(\operatorname{LSD}_{05}\right)$. The differences between the variants are significant if they do not exceed the $\mathrm{LSD}_{05}$ values for the compared pair of the values within the factor.

The reliability of the developed crop prediction models was assessed by the comparison of the calculated during the regression analysis values of the determination coefficients $\left(R^{2}\right)$ of each model. The higher the coefficient is, the more reliable and accurate the model is.

\section{RESULTS}

Sweet corn yield in the ears without husks obtained in the field experiment is represented in Table 1. The values are provided in the following form: the average value by the experimental plot \pm standard deviation (SD) for the certain plot.

All the studied factors affected the yield obtained in the experiment that is testified by the values of the least significant difference, calculated at the probability level of $95 \%\left(\operatorname{LSD}_{05}\right)$. The differences between the variants do not exceed the $\mathrm{LSD}_{05}$ values, so they cannot be considered significant.

The corresponding values of the LAI at two stages of the crop development are presented in
Tables 2 and 3, while the NDVI values for the same estimation periods are provided in Tables 4 and 5. It should be noted that while the LAI values differ significantly throughout the experiment, the differences between the NDVI values are significant only for the comparison of the main effect by the plants density (factor C). All other differences cannot be associated with the influence of the factors studied in the experiment.

The results of the regression analysis of the experimental data testify that there is a strong direct correlation between the LAI and NDVI values and the yield of sweet corn. Coefficients of correlation for the different stages of the crop development averaged to 0.92 for the NDVIbased, and to $0.96-0.97$ for the LAI-based model of the crop productivity.I It was determined that the LAI-based model accuracy is unequal at the different stages of the crop development, and it is better to use the LAI values at the flowering stage of the crop to obtain the most reliable yield prediction.

The results of the regression analysis performed for the combined use of LAI and NDVI showed that there is no reason to complicate the LAI-based model with additional index because the coefficients of determination $R^{2}$ both at the stage of flowering and ripening of the crop were equal to those obtained in the simple LAI-based model (Table 8). Therefore, there is no need in an additional parameter for the yield estimation.

The authors also developed the mathematical regression models for the crop productivity in connection with the LAI and NDVI values at the different stages of the crop development, and these models are presented in Table 9.

The highest percentile of the developed models was 97.92, while the lowest one was about

Table 1. Sweet corn yield in ears without husks in dependence on the studied factors, $\mathrm{t}^{-1} \mathrm{a}^{-1}(2016$ year $\pm \mathrm{SD})$

\begin{tabular}{|c|c|c|c|c|}
\hline \multirow{2}{*}{$\begin{array}{c}\text { Plowing depth, } \\
\text { (Factor A) }\end{array}$} & $\begin{array}{c}\text { Plants density, thousand } \\
\text { pcs. ha- }\end{array}$ & \multicolumn{3}{|c|}{ Fertilization options (Factor B) } \\
\cline { 2 - 5 } & 35 & No fertilization & $\mathrm{N}_{60} \mathrm{P}_{60}$ & $\mathrm{~N}_{120} \mathrm{P}_{120}$ \\
\hline \multirow{4}{*}{$20-22$} & 50 & $2.85 \pm 0.20$ & $5.92 \pm 0.25$ & $7.92 \pm 0.36$ \\
\cline { 2 - 5 } & 65 & $3.02 \pm 0.23$ & $7.34 \pm 0.53$ & $9.90 \pm 0.73$ \\
\cline { 2 - 5 } & 80 & $3.21 \pm 0.31$ & $8.11 \pm 0.45$ & $11.65 \pm 0.61$ \\
\cline { 2 - 5 } & 35 & $3.15 \pm 0.28$ & $7.37 \pm 0.52$ & $10.10 \pm 0.91$ \\
\hline \multirow{3}{*}{$28-30$} & 50 & $3.19 \pm 0.17$ & $5.40 \pm 0.36$ & $6.96 \pm 0.36$ \\
\cline { 2 - 5 } & 65 & $3.57 \pm 0.43$ & $5.82 \pm 0.41$ & $7.79 \pm 0.27$ \\
\cline { 2 - 5 } & 80 & $3.81 \pm 0.28$ & $6.64 \pm 0.41$ & $9.14 \pm 0.31$ \\
\cline { 2 - 5 } & $3.61 \pm 0.28$ & $6.04 \pm 0.27$ & $8.09 \pm 0.41$ \\
\hline
\end{tabular}

Note: $\mathrm{LSD}_{05}$ for the factors and their interaction, $\mathrm{t} \mathrm{ha}^{-1}: \mathrm{A}-0.18 ; \mathrm{B}-0.21 ; \mathrm{C}-0.25 ; \mathrm{ABC}-0.61$. 
Table 2. LAI of sweet corn at the stage of flowering in dependence on the studied factors (2016 year \pm SD)

\begin{tabular}{|c|c|c|c|c|}
\hline \multirow{2}{*}{$\begin{array}{c}\text { Plowing depth, } \\
\text { (Factor A) }\end{array}$} & $\begin{array}{c}\text { Plants density, thousand } \\
\text { pcs. ha }{ }^{-1} \text { (Factor C) }\end{array}$ & No fertilization & $\mathrm{N}_{60} \mathrm{P}_{60}$ & $\mathrm{~N}_{120} \mathrm{P}_{120}$ \\
\cline { 2 - 5 } & 35 & $2.85 \pm 0.20$ & $5.92 \pm 0.25$ & $7.92 \pm 0.36$ \\
\hline \multirow{4}{*}{$20-22$} & 50 & $3.02 \pm 0.23$ & $7.34 \pm 0.53$ & $9.90 \pm 0.73$ \\
\cline { 2 - 5 } & 65 & $3.21 \pm 0.31$ & $8.11 \pm 0.45$ & $11.65 \pm 0.61$ \\
\cline { 2 - 5 } & 80 & $3.15 \pm 0.28$ & $7.37 \pm 0.52$ & $10.10 \pm 0.91$ \\
\hline \multirow{3}{*}{$28-30$} & 35 & $3.19 \pm 0.17$ & $5.40 \pm 0.36$ & $6.96 \pm 0.36$ \\
\cline { 2 - 5 } & 50 & $3.57 \pm 0.43$ & $5.82 \pm 0.41$ & $7.79 \pm 0.27$ \\
\cline { 2 - 5 } & 65 & $3.81 \pm 0.28$ & $6.64 \pm 0.41$ & $9.14 \pm 0.31$ \\
\cline { 2 - 5 } & 80 & $3.61 \pm 0.28$ & $6.04 \pm 0.27$ & $8.09 \pm 0.41$ \\
\hline
\end{tabular}

Note: $\mathrm{LSD}_{05}$ for the factors and their interaction, units: $\mathrm{A}-0.005 ; \mathrm{B}-0.005 ; \mathrm{C}-0.007 ; \mathrm{ABC}-0.017$.

Table 3. LAI of sweet corn at the stage of ripening in dependence on the studied factors (2016 year \pm SD)

\begin{tabular}{|c|c|c|c|c|}
\hline \multirow{2}{*}{$\begin{array}{c}\text { Plowing depth, } \\
\text { (Factor A) }\end{array}$} & $\begin{array}{c}\text { Plants density, thousand } \\
\text { pcs. ha }{ }^{-1} \text { (Factor C) }\end{array}$ & No fertilization & $\mathrm{N}_{60} \mathrm{P}_{60}$ & $\mathrm{~N}_{120} \mathrm{P}_{120}$ \\
\cline { 2 - 5 } & 35 & $1.31 \pm 0.01$ & $1.60 \pm 0.01$ & $2.27 \pm 0.02$ \\
\cline { 2 - 5 } $20-22$ & 50 & $1.81 \pm 0.01$ & $2.19 \pm 0.01$ & $3.11 \pm 0.02$ \\
\cline { 2 - 5 } & 65 & $2.29 \pm 0.01$ & $2.72 \pm 0.01$ & $3.86 \pm 0.02$ \\
\cline { 2 - 5 } & 80 & $2.73 \pm 0.01$ & $3.19 \pm 0.01$ & $4.55 \pm 0.02$ \\
\hline \multirow{3}{*}{$28-30$} & 35 & $1.32 \pm 0.00$ & $1.38 \pm 0.01$ & $1.56 \pm 0.02$ \\
\cline { 2 - 5 } & 50 & $1.84 \pm 0.01$ & $1.87 \pm 0.01$ & $2.14 \pm 0.01$ \\
\cline { 2 - 5 } & 65 & $2.32 \pm 0.01$ & $2.33 \pm 0.01$ & $2.68 \pm 0.01$ \\
\cline { 2 - 5 } & 80 & $2.75 \pm 0.01$ & $2.78 \pm 0.02$ & $3.16 \pm 0.02$ \\
\hline
\end{tabular}

Note: $\mathrm{LSD}_{05}$ for the factors and their interaction, units: A-0.005; B $-0.006 ; \mathrm{C}-0.008 ; \mathrm{ABC}-0.018$.

Table 4. NDVI of sweet corn at the stage of flowering of millet in dependence on the studied factors (2016 year \pm SD)

\begin{tabular}{|c|c|c|c|c|}
\hline \multirow{2}{*}{$\begin{array}{c}\text { Plowing depth, } c m \\
\text { (Factor A) }\end{array}$} & $\begin{array}{c}\text { Plants density, thousand } \\
\text { pcs. ha- }\end{array}$ & \multicolumn{3}{|c|}{ Fertilization options (Factor B) } \\
\cline { 2 - 5 } & 35 & No fertilization & $\mathrm{N}_{60} \mathrm{P}_{60}$ & $\mathrm{~N}_{120} \mathrm{P}_{120}$ \\
\hline \multirow{3}{*}{$20-22$} & 50 & $0.67 \pm 0.08$ & $0.60 \pm 0.08$ & $0.60 \pm 0.09$ \\
\cline { 2 - 5 } & 65 & $0.57 \pm 0.03$ & $0.57 \pm 0.03$ & $0.58 \pm 0.06$ \\
\cline { 2 - 5 } & 80 & $0.63 \pm 0.03$ & $0.57 \pm 0.03$ & $0.53 \pm 0.03$ \\
\hline \multirow{3}{*}{$28-30$} & 35 & $0.62 \pm 0.03$ & $0.62 \pm 0.05$ & $0.60 \pm 0.05$ \\
\cline { 2 - 5 } & 50 & $0.65 \pm 0.13$ & $0.60 \pm 0.10$ & $0.60 \pm 0.00$ \\
\cline { 2 - 5 } & 65 & $0.62 \pm 0.08$ & $0.62 \pm 0.03$ & $0.62 \pm 0.06$ \\
\cline { 2 - 5 } & 80 & $0.65 \pm 0.00$ & $0.63 \pm 0.03$ & $0.62 \pm 0.06$ \\
\hline
\end{tabular}

Note: $\mathrm{LSD}_{05}$ for the factors and their interaction, units: $\mathrm{A}-0.02 ; \mathrm{B}-0.02 ; \mathrm{C}-0.03 ; \mathrm{ABC}-0.08$.

Table 5. NDVI of sweet corn at the stage of ripening in dependence on the studied factors (2016 year \pm SD)

\begin{tabular}{|c|c|c|c|c|}
\hline \multirow{2}{*}{$\begin{array}{c}\text { Plowing depth, } \\
\text { (Factor A) }\end{array}$} & $\begin{array}{c}\text { Plants density, thousand } \\
\text { pcs. ha }{ }^{-1} \text { (Factor C) }\end{array}$ & No fertilization & $\mathrm{N}_{60} \mathrm{P}_{60}$ & $\mathrm{~N}_{120} \mathrm{P}_{120}$ \\
\cline { 2 - 5 } & 35 & $0.58 \pm 0.03$ & $0.58 \pm 0.05$ & $0.57 \pm 0.05$ \\
\hline \multirow{3}{*}{$20-22$} & 50 & $0.55 \pm 0.05$ & $0.55 \pm 0.03$ & $0.50 \pm 0.03$ \\
\cline { 2 - 5 } & 65 & $0.53 \pm 0.03$ & $0.57 \pm 0.06$ & $0.55 \pm 0.01$ \\
\cline { 2 - 5 } & 80 & $0.53 \pm 0.03$ & $0.58 \pm 0.03$ & $0.55 \pm 0.01$ \\
\hline \multirow{3}{*}{$28-30$} & 35 & $0.60 \pm 0.01$ & $0.58 \pm 0.03$ & $0.55 \pm 0.05$ \\
\cline { 2 - 5 } & 50 & $0.58 \pm 0.08$ & $0.57 \pm 0.03$ & $0.58 \pm 0.03$ \\
\cline { 2 - 5 } & 65 & $0.60 \pm 0.01$ & $0.58 \pm 0.03$ & $0.55 \pm 0.05$ \\
\cline { 2 - 5 } & 80 & $0.52 \pm 0.13$ & $0.53 \pm 0.03$ & $0.52 \pm 0.08$ \\
\hline
\end{tabular}

Note: $\mathrm{LSD}_{05}$ for the factors and their interaction, units: $\mathrm{A}-0.02 ; \mathrm{B}-0.02 ; \mathrm{C}-0.03 ; \mathrm{ABC}-0.07$. 
Table 6. Regression analysis of the dependence of sweet corn yield in ears without husks on the LAI values at the different stages of the crop development

\begin{tabular}{|c|c|c|c|c|c|c|c|}
\hline \multicolumn{2}{|c|}{ Coefficient of correlation } & \multicolumn{2}{c|}{ Coefficient of determination } & \multicolumn{2}{c|}{$\begin{array}{c}\text { Coefficient of regression } \\
\text { (slope) }\end{array}$} & \multicolumn{2}{c|}{ Interception } \\
\hline flowering & ripening & flowering & ripening & flowering & ripening & flowering & ripening \\
\hline 0.97 & 0.96 & 0.94 & 0.92 & 3.71 & 2.56 & 0 & 0 \\
\hline
\end{tabular}

Table 7. Regression analysis of the dependence of sweet corn yield in ears without husks on the NDVI values at the different stages of the crop development

\begin{tabular}{|c|c|c|c|c|c|c|c|}
\hline \multicolumn{2}{|c|}{ Coefficient of correlation } & \multicolumn{2}{c|}{ Coefficient of determination } & \multicolumn{2}{c|}{$\begin{array}{c}\text { Coefficient of regression } \\
\text { (slope) }\end{array}$} & \multicolumn{2}{c|}{ Interception } \\
\hline flowering & ripening & flowering & ripening & flowering & ripening & flowering & ripening \\
\hline 0.92 & 0.92 & 0.85 & 0.85 & 10.41 & 11.14 & 0 & 0 \\
\hline
\end{tabular}

Table 8. Regression analysis of the dependence of sweet corn yield in ears without husks on the LAI-NDVI values at the different stages of the crop development

\begin{tabular}{|c|c|c|c|c|c|c|c|c|c|}
\hline \multicolumn{2}{|c|}{ Coefficient of correlation } & \multicolumn{2}{|c|}{$\begin{array}{l}\text { Coefficient of } \\
\text { determination }\end{array}$} & \multicolumn{4}{|c|}{ Coefficient of regression (slope) } & \multicolumn{2}{|c|}{ Interception } \\
\hline flowering & ripening & flowering & ripening & & & & & flowering & ripening \\
\hline \multirow{2}{*}{0.97} & \multirow{2}{*}{0.96} & \multirow{2}{*}{0.94} & \multirow{2}{*}{0.92} & LAI & NDVI & LAI & NDVI & \multirow{2}{*}{0} & \multirow{2}{*}{0} \\
\hline & & & & 3.26 & 1.44 & 2.11 & 2.15 & & \\
\hline
\end{tabular}

Table 9. Linear regression models of sweet corn yield in ears without husks depending on the LAI and NDVI values measured at the different stages of the crop development, where $Y$ is the yield of the crop, LAI and NDVI are the values of the corresponding indexes

\begin{tabular}{|l|c|}
\hline The LAI-based model (the stage of flowering) & $Y=3.71 \times L A I$ \\
\hline The LAI-based model (the stage of ripening) & $Y=2.56 \times L A I$ \\
\hline The NDVI-based model (the stage of flowering) & $Y=10.41 \times N D V I$ \\
\hline The NDVI-based model (the stage of ripening) & $Y=11.14 \times N D V I$ \\
\hline The LAI-NDVI-based model (the stage of flowering) & $Y=3.26 \times L A I+1.44 \times N D V I$ \\
\hline The LAI-NDVI-based model (the stage of ripening) & $Y=2.11 \times L A I+2.15 \times N D V I$ \\
\hline
\end{tabular}

2.08. The best performance of the models could be obtained for the predictions of the crop yield in the variants with full fertilization $\left(\mathrm{N}_{120} \mathrm{P}_{120}\right)$; conversely, the worst performance, is obtained at the prediction of the yields in the non-fertilized variants due to the higher disparity between the LAI, NDVI and yields in these variants. The comparison of the true and predicted values of the crop yields is presented in Table 10.

It is evident that the NDVI-based model provided considerably higher average residuals values in comparison to the LAI-based and the LAI-NDVI-based one: $2.20-2.21$ versus 1.52 1.69 versus $1.67-2.21$. The range of the residuals was considerably higher under the implementation of the NDVI-based model: $-4.12 \ldots$ 5.72 against $-3.84 \ldots 2.97$ for the LAI-based, and $-3.75 \ldots 5.52$ for the LAI-NDVI-based one. Therefore, it is advisable to rely more on the LAI-based yield predictions (or complex LAINDVI) than on the NDVI-based ones. It was also found that the simple LAI-based model is more accurate even than the combined LAINDVI one. However, the improvement of the technique of the NDVI screening, firstly, through the decrease of the noise caused by the cloudiness and other unfavorable weather phenomena, can significantly increase the performance of the NDVI-based prediction models. The combination of the NDVI with other additional indices (not obligatory of the crop as the LAI, but of the meteorological and soil parameters) could possibly help to significantly improve the crop model performance. 
Table 10. The comparison of true and predicted yields of sweet corn by using the LAI and NDVI based crop models by the residuals, $\mathrm{tha}^{-1}$

\begin{tabular}{|c|c|c|c|c|c|c|}
\hline \multirow{2}{*}{$\begin{array}{l}\text { The number of the } \\
\text { simulated pair }\end{array}$} & \multicolumn{2}{|c|}{ LAl-based residuals } & \multicolumn{2}{|c|}{ NDVI-based residuals } & \multicolumn{2}{|c|}{ LAI-NDVI-based residuals } \\
\hline & Flowering stage & Ripening stage & Flowering stage & Ripening stage & Flowering stage & Ripening stage \\
\hline 1 & -0.19 & -0.50 & -4.12 & -3.65 & -3.65 & -1.16 \\
\hline 2 & -1.17 & -1.61 & -2.91 & -3.11 & -3.11 & -1.98 \\
\hline 3 & -2.06 & -2.65 & -3.35 & -2.73 & -2.73 & -2.76 \\
\hline 4 & -3.08 & -3.84 & -3.30 & -2.79 & -2.79 & -3.75 \\
\hline 5 & 1.84 & 1.82 & -0.85 & -0.58 & -0.58 & 1.30 \\
\hline 6 & 1.70 & 1.73 & 0.89 & 1.21 & 1.21 & 1.53 \\
\hline 7 & 0.88 & 1.15 & 1.34 & 1.80 & 1.80 & 1.14 \\
\hline 8 & -1.24 & -0.80 & 1.64 & 0.87 & 0.87 & -0.61 \\
\hline 9 & 2.17 & 2.11 & 1.67 & 1.61 & 1.61 & 1.90 \\
\hline 10 & 1.89 & 1.94 & 3.97 & 4.33 & 4.33 & 2.26 \\
\hline 11 & 1.48 & 1.77 & 5.72 & 5.52 & 5.52 & 2.32 \\
\hline 12 & -2.07 & -1.55 & 3.65 & 3.97 & 3.97 & -0.69 \\
\hline 13 & 0.07 & -0.19 & -3.06 & -3.49 & -3.50 & -0.89 \\
\hline 14 & -0.70 & -1.14 & -2.88 & -2.93 & -2.93 & -1.56 \\
\hline 15 & -1.61 & -2.13 & -2.75 & -2.87 & -2.88 & -2.38 \\
\hline 16 & -2.85 & -3.43 & -1.39 & -2.15 & -2.15 & -3.31 \\
\hline 17 & 1.99 & 1.87 & -0.85 & -1.10 & -1.10 & 1.24 \\
\hline 18 & 1.07 & 1.03 & -0.22 & -0.49 & -0.49 & 0.65 \\
\hline 19 & 0.63 & 0.68 & 1.12 & 0.14 & 0.14 & 0.47 \\
\hline 20 & -1.08 & -1.08 & -0.21 & 0.10 & 0.10 & -0.97 \\
\hline 21 & 2.62 & 2.97 & 0.71 & 0.83 & 0.83 & 2.48 \\
\hline 22 & 1.74 & 2.31 & 1.34 & 1.29 & 1.29 & 2.02 \\
\hline 23 & 1.65 & 2.28 & 2.69 & 3.01 & 3.01 & 2.30 \\
\hline 24 & -0.81 & 0.00 & 2.36 & 2.33 & 2.33 & 0.30 \\
\hline Aver. residual value, \pm & 1.52 & 1.69 & 2.21 & 2.20 & & \\
\hline
\end{tabular}

\section{DISCUSSION}

Yield forecasting is a highly important task of modern agricultural science that ensures national and global food safety (Horie et al., 1992). Recently, the NDVI has been used to forecast productivity of different crops under various environmental conditions. The results of some studies are quite encouraging but at the same time there are some studies that report certain difficulties and inconveniences related to the noisy data of the NDVI space screening that resulted in considerable inaccuracy of the crop yielding models. For example, Quarmby et al. (1993) reported successful use of the NDVI data for operational monitoring of the conditions of such crops as wheat, cotton, rice and corn in the area of Northern Greece. They have also claimed quite a high reliability and accuracy of a simple linear regression model of "NDVI-yield" inter-relationship for every studied crop and suggested that NDVI is very good for the purposes of crop productivity forecasting. The corn production estimations based on the NDVIbased model with the coefficient of regression R 0.75 were performed by Lewis et al. (1998), who claimed that the NDVI-based simple regression models are very encouraging. A successful introduction of the NDVI in the complex model for estimation of corn and soybean yields has been performed by Prasad et al. (2006). However, their model did not use the NDVI as a selfsufficient individual index for the crop yield as in our study. The study, which was conducted in order to predict the rice yields in China, revealed that the NDVI tends to always have a positive correlation with the crop yield that agrees with the results of our study (Huang et al., 2013). In this study, the authors reported about a relatively low error of the NDVI-based yield model of the maximum 5.82\%. Balaghi et al. (2008) tried to use the NDVI, rainfall and temperature data for an early prediction of wheat yields in Morocco 
by the empirical regression model and succeeded. Besides, scientists stated that the NDVI reliability in the crop conditions assessment increases, if the indices of later stages of the crop vegetation period are used (Thomason et al., 2007), which agrees with our results (more reliable prediction of yield by the NDVI at the later stage of the crop development). Rasmussen (1992) stated that it is possible to assess the millet yields and production levels based on the NDVI integral values. The scientist reported the sufficient accuracy of the iNDVI-based predictive model.

Even though a number of scientists claim good performance of the NDVI-based models for crops, there are some recent scientific studies that are not as optimistic in this question. For example, Fang et al. (2011) conducted a great testing of four different crop models using two different approaches: the models, based on a certain separate index, and the model, based on the complex use of the indices. Fang et al. (2011) used three main indices for the estimation of the crops: LAI, NDVI, and the enhanced vegetation index (EVI). The results of their study revealed that the predicted yield of corn was quite different at the use of different modeling approaches. The best performance was provided by the combined EVILAI model (with the discrepancy of only 3.5\% in comparison to the actual data). The LAI-based model resulted in $8.6 \%$ discrepancy, and the separate use of the EVI and NDVI provided the worst results (the discrepancy of 13-21\%). Thus, Fang et al. (2011) concluded that it is unacceptable to use the NDVI or EVI values as self-sufficient markers of corn productivity. This conclusion is in the agreement with ours, with the only distinction that we obtained even lower reliability of the NDVI-based prediction of the crop yield. In addition, Aparicio et al. (2000) provided the proof that the use of the NDVI for grain yield of durum wheat is justified only at the LAI level of the crops less than 3. At higher values of the LAI, the NDVI-based model usefulness is questionable.

Nevertheless, the LAI-based crop prediction models are very good. In the conducted study, we obtained the highest value of the determination coefficient of 0.94 , while other scientists obtained the values of 0.49-0.55 for rice (Son et al., 2013), and $0.23-0.48$ for winter wheat yields simulation (Huang et al., 2015). It has to be mentioned that the values of the determination coefficient of 0.75 and lower could not be considered as the markers of high reliability and accuracy of the developed prediction models for crops. Therefore, LAI might not be used for every crop under every agricultural and environmental condition.

Scientists suggest that it might be very useful to elaborate the crop models, which will be able to handle and operate with the complex of the LAI, NDVI, and other remotely or directly sensed indices related to the crop productivity, because our results showed that the combination of only the LAI and NDVI might be insufficient for significant improvement of the model. Now, there is no generally accepted point of view on the use of the simple or complex NDVI-based models for crops prediction. Most researchers claim that if precise predictions are beeded it would be better to implement complex models. However, the indices that must be included in the complex yielding model are still a subject of debates and further investigations are required to come up with a final conclusion in this question. Another opinion is that in fact both simple single-index-based models and complex multi-index models are needed because both these types of models are useful for different purposes (Boote et al., 1996).

Jiang et al. (2004) provided the report on the study where they implemented an artificial neural network approach to the creation of the model for yield estimation using remotely sensed indices and claimed very high reliability and accuracy of the created model. Perhaps, the implementation of modern computational techniques, such as artificial neural networks, is one of the most prospective ways to develop highly accurate yielding models for crops.

\section{CONCLUSIONS}

Even though the remotely sensed NDVI is an important modern index reflecting conditions of crops, it has been found out that it is less suitable for reliable and accurate prediction of crops productivity $\left(\mathrm{R}^{2}=0.85\right)$ in comparison with the directly measured LAI. LAI is an old index used for the assessment of crops status at the concrete moment of their development; however, it appeared to be more reliable for the productivity prediction than the NDVI $\left(\mathrm{R}^{2}=0.92-0.94\right)$. It has also been discovered that it is better to use the values of the LAI at the flowering stage of sweet corn crops and the NDVI values - regardless the stage of ripening - in order to obtain more accurate yield predictions. The use of the indices 
obtained in another time resulted in the decrease of prediction reliability. However, comparatively lower accuracy of the NDVI-based prediction could be put upon the fact of noisy NDVI data provided by the monitoring service, and imperfection of the reflection by the NDVI of the crops canopy condition due to the weather conditions and soil albedo. Modern techniques for obtaining more accurate NDVI data should be applied into the modern remote sensing systems to prevent the occurrence of spoilt and noisy datasets (Hird and McDermid, 2009). The unnecessary complication of the LAI-based model for yield prediction by the inclusion of additional input of the NDVI was discovered. Further studies in this area are required to be conducted for other crops and environmental conditions because of a great importance of comprehensive and efficient use of modern methods of remote sensing of environment in theoretical agricultural science and practice.

\section{REFERENCES}

1. Aparicio N., Villegas D., Casadesus J., Araus J.S., Royo C. 2000. Spectral vegetation indices as nondestructive tools for determining durum wheat yield. Agron. J., 92(1), 83-91. http://doi.org/10.2134/ agronj2000.92183x

2. Atzberger C. 2013. Advances in remote sensing of agriculture: Context description, existing operational monitoring systems and major information needs. Remote Sens., 5(2), 949-981. http://doi. org/10.3390/rs5020949

3. Balaghi R., Tychon B., Eerens H., Jlibene M. 2008. Empirical regression models using NDVI, rainfall and temperature data for the early prediction of wheat grain yields in Morocco. Intern. J. Appl. Earth Observ. Geoinform., 10(4), 438-452. https:// doi.org/10.1016/j.jag.2006.12.001

4. Boote K.J., Jones J.W., Pickering N.B. 1996. Potential uses and limitations of crop models. Agron. J., 88(5), 704-716. http://doi.org/10.2134/agronj1996. $00021962008800050005 \mathrm{x}$

5. Bréda N.J.J. 2003. Ground-based measurements of leaf area index: a review of methods, instruments and current controversies. J. Experiment. Bot., 54(392), 2403-2417. http://doi.org/10.1093/jxb/erg263

6. Carlson T.N., Ripley D.A. 1997. On the relation between NDVI, fractional vegetation cover, and leaf area index. Remote Sens. Environ., 62(3), 241-252. https://doi.org/10.1016/S0034-4257(97)00104-1

7. Daughtry C.S.T. 1990. Direct measurements of canopy structure. Remote Sens. Rev., 5(1), 45-60. http://doi.org/10.1080/02757259009532121
8. Fang H., Liang S., Hoogenboom G. 2011. Integration of MODIS LAI and vegetation index products with the CSM-CERES-Maize model for corn yield estimation. Intern. J. Remote Sens., 32(4), 10391065. http://doi.org/10.1080/01431160903505310

9. Gamon J.A., Field C.B., Goulden M.I., Griffin K.L., Hartley A.E., Joel G., Penuetas J., Valentini R. 1995. Relationships between NDVI, canopy structure, and photosynthesis in three Californian vegetation types. Ecol. Appl., 5(1), 28-41. https:// doi.org/10.2307/1942049

10. Hird J.N., McDermid G.J. 2009. Noise reduction of NDVI time series: An empirical comparison of selected techniques. Remote Sens. Environ., 113(1), 248-258. http://doi.org/10.1016/j.rse.2008.09.003

11. Horie T., Yajima M., Nakagawa H. 1992. Yield forecasting. Agric. Syst., 40(1-3), 211-236. http://doi. org/10.1016/0308-521X(92)90022-G

12. Huang J., Tian L., Liang S., Ma H., Becker-Reshef I., Huang Y., Su W., Zhang X., Zhu D., Wu W. 2015. Improving winter wheat yield estimation by assimilation of the leaf area index from Landsat TM and MODIS data into the WOFOST model. Agric. For. Meteorol., 204, 106-121. http://doi.org/10.1016/j. agrformet.2015.02.001

13. Huang J., Wang X., Li X., Tian H., Pan Z. 2013. Remotely sensed rice yield prediction using multi-temporal NDVI data derived from NOAA's-AVHRR. PloS One, 8(8), e70816. https://doi.org/10.1371/ journal.pone. 0070816

14. Jiang D., Yang X., Clinton N., Wang N. 2004. An artificial neural network model for estimating crop yields using remotely sensed information. Intern. J. Remote Sens. 25(9): 1723-1732. http://doi. org/10.1080/0143116031000150068

15. Kouadio L., Newlands N.K., Davidson A., Zhang Y., Chipanshi A. 2014. Assessing performance of MODIS NDVI and EVI for seasonal crop yield forecasting at the ecodistrict scale. Remote Sens., 6(10), 10193-10214. https://doi.org/10.3390/rs61010193

16. Lewis J.E., Rowland J.J., Nadeau A. 1998. Estimating maize production in Kenya using NDVI: some statistical considerations. Intern. J. Remote Sens., 19(13), 2609-2617. http://doi. org/10.1080/014311698214677

17. Liu Q., Huete A. 1995. A feedback based modification of the NDVI to minimize canopy background and atmospheric noise. IEEE T. Geosci. Remote Sens., 33(2), 457-465. https://doi.org/ 10.1109/ TGRS.1995.8746027

18. Maas S.J. 1988. Use of remotely-sensed information in agricultural crop growth models. Ecol. Model., 41(3-4), 247-268. http://doi. org/10.1016/0304-3800(88)90031-2

19. Myneni R.B., Hall F.G., Sellers P.J., Marshak A.L.. 1995. The interpretation of spectral vegetation 
indexes. IEEE T. Geosci. Remote Sens., 33(2), 481486. http://doi.org/10.1109/36.377948

20. Prasad A.K., Chai L., Singh R.P., Kafatos M. 2006. Crop yield estimation model for Iowa using remote sensing and surface parameters. Intern. J. Appl. Earth Observ. Geoinform., 8(1), 26-33. https://doi. org/10.1016/j.jag.2005.06.002

21. Quarmby N.A., Milnes M., Hindle T.L., Silleos N. 1993. The use of multi-temporal NDVI measurements from AVHRR data for crop yield estimation and prediction. Intern. J. Remote Sens., 14(2), 199210. https://doi.org/10.1080/01431169308904332

22. Rasmussen M.S. 1992. Assessment of millet yields and production in northern Burkina Faso using integrated NDVI from the AVHRR. Intern. J. Remote Sens., 13(18), 3431-3442. http://doi. org/10.1080/01431169208904132

23. Sellers P.J. 1985. Canopy reflectance, photosynthesis and transpiration. Intern. J. Remote Sens., 6(8), 1335 1372. http://doi.org/10.1080/01431168508948283

24. Son N.T., Chen C.F., Chen C.R., Chang L.Y., Duc H.N., Nguyen L.D. 2013. Prediction of rice crop yield using MODIS EVI-LAI data in the Mekong Delta, Vietnam. Intern. J. Remote Sens., 34(20), 7275-7292. http://doi.org/10.1080/01431161.201 3.818258

25. Thomason W.E., Phillips S.B., Raymond F.D. 2007. Defining useful limits for spectral reflectance measures in corn. J. Plant Nutr., 30(8), 1263-1277. http://doi.org/10.1080/01904160701555176

26. Triola M.F. 2013. Elementary statistics using Excel. Pearson.

27. Ushkarenko V.O., Kokovikhin S.V., Holoborodko S.P., Vozhehova R.A. 2014. The methodology of the field experiment (irrigated agriculture): the textbook. Hrin D.S., Kherson. 